\title{
Short communication: Neonatal calves coagulate first-milking colostrum and produce a large curd for efficient absorption of immunoglobulins after first ingestion
}

\author{
T. Miyazaki, ${ }^{*}$ K. Okada, ${ }^{*}$ and M. Miyazaki $\dagger^{1}$ \\ *Department of Veterinary Medicine, and \\ †Department of Biological Chemistry and Food Sciences, Faculty of Agriculture, Iwate University, Iwate 020-8550, Japan
}

\begin{abstract}
Calves are fed milk and milk replacer for their growth until approximately 2 mo after birth. During this period, their abomasa produce curd and whey from milk. It has been thought that curd formation is important for digestion and absorption of milk nutrients and immune substances in calves. However, no study has been done observing abomasal contents in neonatal calves after first ingestion of first milking colostrum. Here we report curd formation in neonatal calves and its physiological function with a focus on immunoglobulin absorption. We first examined curd formation by ultrasonography in 3 neonatal calves after first ingestion of first-milking colostrum. Between 0.5 and $8 \mathrm{~h}$ after colostrum ingestion, a curd was visualized as a large echogenic image with a clear outline, which was surrounded by an anechoic image corresponding to whey. We next compared serum IgG and IgA concentrations in 10 calves fed the pooled colostrum and 7 calves fed the whey solution that did not coagulate into curds. Serum from 1 calf in the pooled colostrum sample set was excluded due to incomplete curd formation in that the whole colostrum did not coagulate into a large mass of curd and a portion of the colostrum remained as its residue caseins detectable from the abomasal fluid. Serum $\operatorname{IgG}$ and IgA concentrations were significantly higher in the 9 calves fed the colostrum than the 7 calves fed the whey solution. One calf exhibiting incomplete curd formation showed low levels of serum IgG and IgA after ingestion, similar to the calves fed the whey solution. These results indicate that curd formation is associated with $\operatorname{IgG}$ and $\operatorname{IgA}$ absorption in neonatal calves after first ingestion of colostrum.
\end{abstract}

Key words: neonatal calf, curd, immunoglobulin G, colostrum

Received February 27, 2017.

Accepted May 10, 2017.

${ }^{1}$ Corresponding author: mmasao@iwate-u.ac.jp

\section{Short Communication}

Colostrum is a rich source of nutrients and immune substances for neonatal calves (Tsioulpas et al., 2007; Elizondo-Salazar and Heinrichs, 2009). Neonatal calves can absorb colostral IgG by intestinal pinocytosis within first $24 \mathrm{~h}$ after birth (Jochims et al., 1994; Kaup et al., 1996). Therefore, a common management technique is to feed colostrum to neonatal calves during this period (Quigley and Drewry, 1998; Godden, 2008). Quality and quantity of colostrum and age of first feeding are mainly focused as important factors for efficient IgG absorption from colostrum in neonatal calves (Stott and Fellah, 1983; Furman-Fratczak et al., 2011; Osaka et al., 2014; Yang et al., 2015; Halleran et al., 2017). It has been also suggested that abomasal curd formation is involved in the absorption of colostral IgG (Cruywagen, 1990; Longenbach and Heinrichs, 1998; Gregory, 2003).

Through curd formation, milk components are separated into curd and whey in the abomasum of calves. Milk caseins and lipids are major contents of the curd, whereas whey contains other milk proteins such as immunoglobulins and lactoglobulins, lactose, and minerals. A study showed that plasma IgG levels are higher in neonatal calves fed unadjusted colostrum than in neonatal calves fed colostrum with added oxalic acid to inhibit milk coagulation (Cruywagen, 1990). Additionally, one report showed that over one-third of abomasal fluid samples obtained from neonatal calves lacked enzyme activities for curd formation, and serum levels of $\gamma$-glutamyl transferase (GGT), which is used as an indicator of IgG absorption, were higher in calves fed colostrum with rennet than in calves fed only colostrum (Gregory, 2003). We recently found that some neonatal calves exhibited low levels of IgG and oligosaccharides including lactose, candidates absorbed by intestinal pinocytosis, until $12 \mathrm{~h}$ after first ingestion of first-milking colostrum (Miyazaki et al., 2017). Considering also our previous finding that $28 \%$ (95\% CI, 15-46\%) calves $(2$ d old) exhibited no curd formation after feeding a clot- 
ting milk replacer (Miyazaki et al., 2010), we hypothesized that there is individual variation in abomasal conditions for curd formation among neonatal calves and the variations may cause differences in colostral IgG and oligosaccharide absorptions.

In our previous studies, ultrasonography showed abomasal curd formation only in calves older than 2 $\mathrm{d}$ after feeding fresh milk and some milk replacers (Miyazaki et al., 2009; Okada et al., 2009). However, no studies have focused on abomasal curd formation of neonatal calves after first ingestion of first-milking colostrum. We proposed that it is necessary to examine abomasal curd formation in individual neonatal calves using ultrasonography. Such study will also help to discuss why there was a wide variation in apparent efficiency of absorption (AEA) of IgG in calves (Stott and Menefee, 1978), and why there were conflicting results regarding the IgG absorption in neonatal calves after feeding sodium bicarbonate-containing colostrum replacers; such replacers increased serum IgG concentrations in neonatal calves after ingestion (Morrill et al., 2010; Cabral et al., 2012), or not (Cabral et al., 2011, 2014).

The purpose of this study is to examine whether a large mass of curd is produced in individual neonatal calves after first ingestion of first-milking colostrum, as well as calves older than $2 \mathrm{~d}$. We also examined the existence of calves that exhibited incomplete curd formation, such as small curds and no curd. Furthermore, we compared serum IgG and IgA levels between neonatal calves with and without curd formation under evidence that each neonatal calf produced curd or not. Finally we discussed whether abomasal curd formation is involved in AEA of IgG in neonatal calves after first ingestion of first-milking colostrum.

This study was approved by the Animal Research Committee and followed the guidelines for Animal Experiments at Iwate University. First-milking colostrum (approximately $100 \mathrm{~L}$ ) was collected from 37 Holstein cows at 5 private dairy farms. Then, the pooled colostrum (aliquot $2 \mathrm{~L}$ ) was divided into plastic bags; 20 of the 50 bags were immediately stored at $-20^{\circ} \mathrm{C}$ until later feeding. In the remaining 30 bags, $40 \mathrm{~mL}$ of 100 $\mathrm{mg} / \mathrm{mL}$ of rennet (MP Biomedical, Santa Ana, CA) solution in $0.1 M$ sodium phosphate buffer $(\mathrm{pH} 6.3$ ) was added to each bag and incubated at $38^{\circ} \mathrm{C}$ for $2 \mathrm{~h}$ until a large clot of curd and yellowish transparent whey were observed. The whey was then separated from curds using a strainer and pooled in a plastic bucket. The whey (aliquot $2 \mathrm{~L}$ ) was divided into plastic bags containing $260 \mathrm{~g}$ (1,350 kcal) of human milk formula (Sukoyaka, Bean Stalk Snow Co., Ltd., Tokyo, Japan) as supplements, whose amounts were decided based on the reported dairy cow colostrum contents of protein, fat, and carbohydrates (Tsioulpas et al., 2007; Elizondo-Salazar and Heinrichs, 2009). The pooled whey with milk formula (whey solution) was stored at $-20^{\circ} \mathrm{C}$ until later feeding.

Curd formation of the pooled colostrum was examined in in vitro rennet coagulation tests according to a modified method of our previous study (Miyazaki et al., 2009). Briefly, $10 \mathrm{~mL}$ of the colostrum was mixed with $200 \mu \mathrm{L}$ of $100 \mathrm{mg} / \mathrm{mL}$ rennet solution, and then the mixture was incubated at $38^{\circ} \mathrm{C}$ for $2 \mathrm{~h}$. Coagulation was evaluated every $30 \mathrm{~min}$ by filtering the mixture through a 1.4-mm testing sieve (Tokyo Screen Co., Tokyo, Japan). The curd on the sieve was weighed. The IgG concentrations in the filtrate were measured using a bovine IgG ELISA quantitation set (Bethyl Laboratories Inc., Montgomery, TX). Curd formation of the pooled colostrum in the presence of amniotic fluid was also examined in in vitro rennet coagulation tests. Five milliliters of the colostrum was mixed with $5 \mathrm{~mL}$ of amniotic fluid that was obtained from 3 Holstein dams during cesarean section, and the mixture was incubated with $200 \mu \mathrm{L}$ of $100 \mathrm{mg} / \mathrm{mL}$ rennet solution as described above.

In the primary experiment, 3 male Holstein-Friesian calves, with a mean BW at birth of $48.5 \pm 2.2 \mathrm{~kg}$ (mean $\pm \mathrm{SD}$ ), were used for the temporal observation of abomasal curd formation after first ingestion of first-milking colostrum. Their physical conditions were evaluated based on appearance, vitality, and blood cell counts. Calves were fed the colostrum once at a volume of $4 \%$ of $\mathrm{BW}$ at $38^{\circ} \mathrm{C}$ using a rubber nipple attached to a bucket within $4.1 \pm 0.4 \mathrm{~h}$ (mean $\pm \mathrm{SD}$ ) after birth. Ultrasonographic images of the abomasal contents were captured using a HS- $1500 \mathrm{~V}$ ultrasonic system equipped with a HLS-375 $5.0-\mathrm{MHz} 50-\mathrm{mm}$ linear transducer (Honda Electronics Co., Ltd., Aichi, Japan) immediately before $(0)$ and $0.5,1,2$, and $8 \mathrm{~h}$ after first ingestion of the pooled colostrum. Two or 3 sequential captured frames were combined into 1 picture to show abomasal contents in cross-sectional and longitudinal sectional images using Photoshop software (Adobe Systems Inc., San Jose, CA).

In the secondary experiment, 17 Holstein calves (12 male and 5 female) from 6 private dairy farms in Hokkaido, Japan, were separated from their dams before suckling occurred, and housed individually in calf hutches. They were divided into 2 feeding groups. Ten of the 17 calves were fed $2 \mathrm{~L}$ of pooled colostrum and the remaining 7 calves were fed $2 \mathrm{~L}$ of pooled whey solution, at $38^{\circ} \mathrm{C}$ within $3 \mathrm{~h}$ after birth. A bias was present regarding the numbers of calves between the 2 groups. This was due to the following reason. Consider- 
ing our previous report that approximately 28\% (95\% CI, 15-46\%) of calves may exhibit no abomasal curd formation (Miyazaki et al., 2010), it was necessary to feed the pooled colostrum to over 10 calves for obtaining serum samples of 7 calves that formed curd. Therefore, we fed the pooled colostrum to 10 calves. Curd formation of the abomasum in each calf was examined by ultrasonographic imaging of abomasal contents at 2 $\mathrm{h}$ after the feeding. Blood samples were collected from a jugular vein into 3.5-mL serum Vacutainer tubes (Becton, Dickinson and Company, Franklin Lakes, NJ) 6 to $7 \mathrm{~h}$ after the first feeding and immediately before the second feeding. Serum IgG and $\operatorname{Ig} A$ concentration were measured using bovine IgG and IgA ELISA quantitation sets (Bethyl Laboratories Inc., Montgomery, TX), respectively. The AEA of IgG was calculated by using the following equation that was reported previously (Halleran et al., 2017):

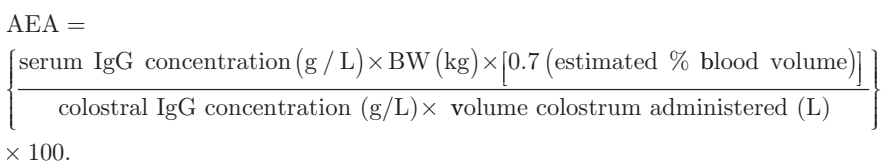

Serum total protein and GGT were measured by using TP CoMe Modular P large and Liquitech $\gamma$-GT IFCC (Roche Diagnostics K.K., Tokyo, Japan), respectively. Each value was compared between calves fed the pooled colostrum and calves fed the pooled whey solution by Student's $t$-test. All data were expressed as means \pm standard error. A $P$-value $<0.05$ was considered significant. Abomasal fluid was collected from 4 of the 10 calves fed the pooled colostrum via abdominocentesis with an 18-gauge needle $2 \mathrm{~h}$ after the first ingestion of the pooled colostrum under local anesthesia with $2 \%$ procaine hydrochloride. Ultrasonography was used to confirm the optimal location for abdominocentesis, where there was the possible largest lumen of abomasum adjacent to the abdominal wall without disturbance of other organs. The $\mathrm{pH}$ of abomasal fluid was measured by a $\mathrm{pH}$ meter (TPX-90, Toko Chemical Laboratories Co., Ltd., Tokyo, Japan). Coagulation abilities of the abomasal fluid were examined by in vitro coagulation tests in which $100 \mu \mathrm{L}$ of the abomasal fluid were incubated with $1 \mathrm{~mL}$ of the pooled colostrum for 0.5 h. The protein concentrations were measured by the Bradford method using BSA as the standard. Protein composition of the abomasal fluid (aliquot $20 \mu \mathrm{g}$ ) was examined by SDS-PAGE (12\% gel) under nonreducing conditions, and the gel was stained with Coomassie Brilliant Blue R-250.

In this study, we first examined curd formation in 3 neonatal calves over $8 \mathrm{~h}$ after first ingestion of the pooled first-milking colostrum. Before feeding the colostrum, in vitro assays confirmed that the pooled colostrum is coagulated by incubation with rennet solution under both the presence and absence of amniotic fluid (Supplemental Figure S1; https:/ /doi.org/10.3168/ jds.2017-12808). All calves suckled whole amounts of the pooled colostrum within 10 min without assistance and exhibited no physiological problems during the experimental period. Figure 1 shows representative ultrasonographic images of abomasal contents of the 3 neonatal calves. Abomasal contents were observed from both cross-sectional (left panels) and longitudinal sectional topographical views (right panels) between immediately before $(0 \mathrm{~h})$ and $8 \mathrm{~h}$ after the first ingestion of the pooled colostrum. At $0 \mathrm{~h}$, the abomasal content was visualized as an anechoic image in the 3 calves. This corresponds to abomasal fluid, which is made up of digestive juice of the calves with or without amniotic fluid of the dams. At $0.5 \mathrm{~h}$ after the ingestion, a curd was visualized as a large echogenic image with a clear outline, which was surrounded by an anechoic image corresponding to whey in their abomasum. The size of the curd was unchanged at 0.5 and $1 \mathrm{~h}$, but decreased slightly at 2 and $8 \mathrm{~h}$ after ingestion. The clear echogenic image corresponding to the curd was also observed $8 \mathrm{~h}$ after the ingestion in the 3 calves.

We next compared serum concentrations of $\operatorname{Ig} G, \operatorname{Ig} A$, GGT, and total proteins between neonatal calves with and without curd formation. We prepared the whey solution from the pooled colostrum to generate neonatal calves that cannot produce curd after ingestion of the same level of IgG with the pooled colostrum. Contents of protein, fat, $\operatorname{IgG}$, and $\operatorname{IgA}$ were $14.5 \%$, $5.1 \%, 54.5 \mathrm{~g} / \mathrm{L}$, and $29.7 \mathrm{~g} / \mathrm{L}$ in the pooled colostrum and $10.2 \%, 2.6 \%, 59.4 \mathrm{~g} / \mathrm{L}$, and $18.2 \mathrm{~g} / \mathrm{L}$ in the whey solution, respectively. Both the pooled colostrum and the whey solution showed a $\mathrm{pH}$ of 6.1 . In vitro assays confirmed that the whey solution was not coagulated by the incubation with rennet solution, in contrast to the pooled colostrum (Supplemental Figure S2; https:/ / doi.org/10.3168/jds.2017-12808).

We fed the pooled colostrum and the whey solution to 10 calves and 7 calves, respectively. In ultrasonographic imaging, a large echogenic image with a clear outline, corresponding to a large curd, was shown in 9 of the 10 calves $2 \mathrm{~h}$ after the feeding of colostrum. In contrast, in the remaining calf, we observed some echogenic images with clear outlines that may correspond to small curds (Figure 2A). The abomasal fluid samples of the calf and 3 control calves with a large curd showed $\mathrm{pH}$ values of 5.4 and $5.5 \pm 0.1$, respectively. All of the samples with opalescent color coagulated the colostrum in in vitro assays. Protein concentrations of the abomasal fluid samples were $4.7 \mathrm{mg} / \mathrm{mL}$ in the calf and $10.6 \pm 1.2 \mathrm{mg} /$ $\mathrm{mL}$ in 3 control calves. The SDS-PAGE detected IgG, 


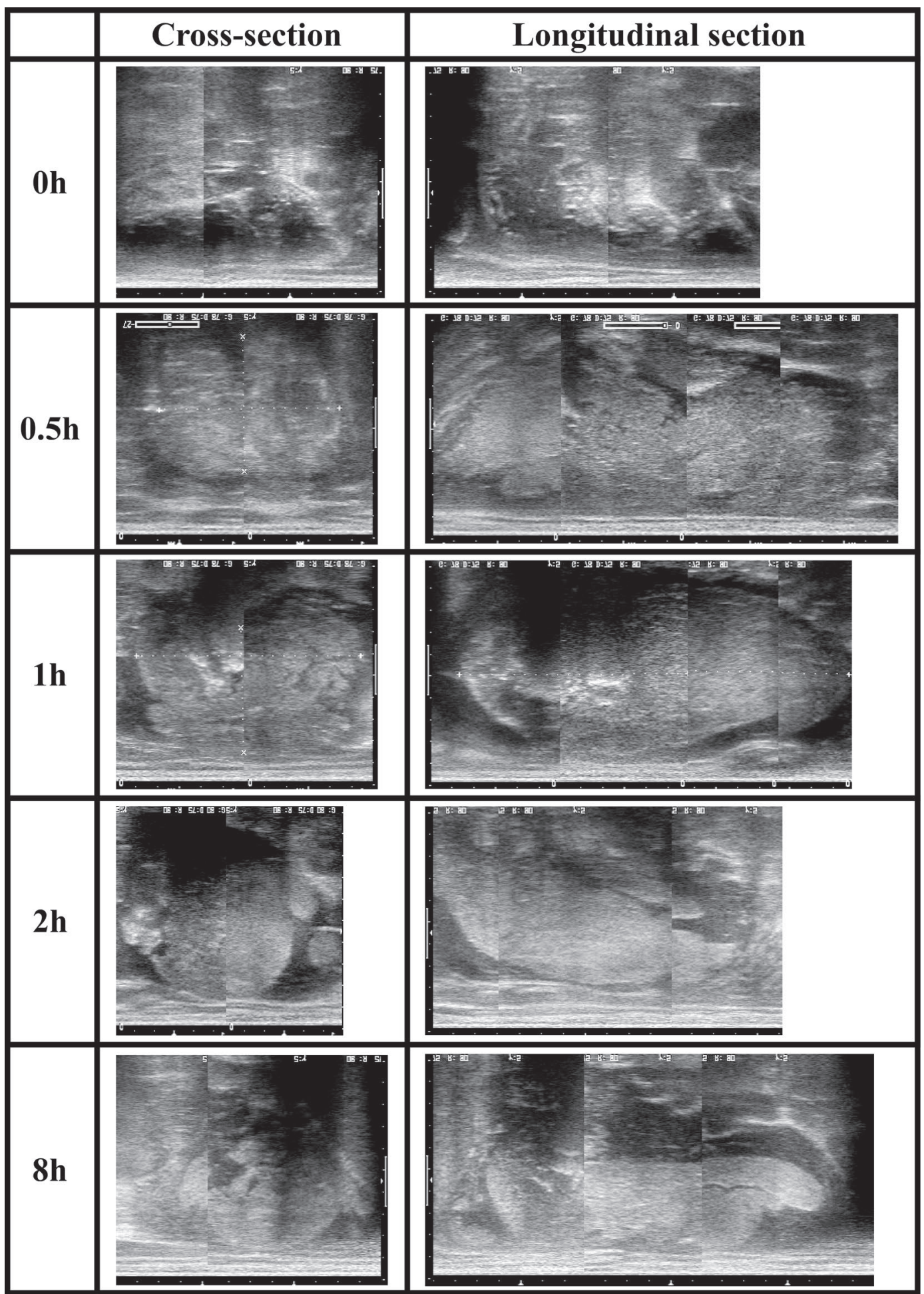

Figure 1. Ultrasonographic images of the abomasal curd in a calf until $8 \mathrm{~h}$ after first ingestion of first-milking colostrum. Upper, lower. right, and left of cross-sectional images correspond to dorsal, ventral, right, and left of calf bodies, respectively. Upper, lower, right, and left of longitudinal sectional images correspond to dorsal, ventral, caudal, and cranial of calf bodies, respectively.

$\alpha-\mathrm{LA}$, and $\beta-\mathrm{LG}$, but not $\alpha-\mathrm{CN}$ and $\beta-\mathrm{CN}$, as major contents in control abomasal fluid, as well as the whey solution prepared by the in vitro rennet coagulation test (Figure 2B). In contrast, the abomasal fluid of the calf with small curds had $\alpha-\mathrm{CN}$ and $\beta-\mathrm{CN}$, in addition to $\alpha$-LA and $\beta$-LG bands. Band density of $\operatorname{IgG}$ was 
markedly decreased in the calf as compared with the control calves. These results suggest that one of the 10 calves fed the pooled colostrum exhibited incomplete curd formation in which the colostrum coagulated into small curds, but not into a large curd, and a portion of the colostrum remained without coagulation. We excluded serum data of the calf for statistical analysis.

Serum IgG concentrations were significantly higher $(P=0.0126)$ in the 9 calves fed the pooled colostrum $(3.8 \pm 1.6 \mathrm{~g} / \mathrm{L})$ than in the 7 calves fed the whey solution $(2.1 \pm 0.6 \mathrm{~g} / \mathrm{L}$; Figure $3 \mathrm{~A})$. The AEA of IgG were significantly higher $(P=0.007)$ in the 9 calves fed the pooled colostrum $(11.1 \pm 1.5 \%)$ than the 7 calves fed the whey solution $(5.7 \pm 0.5 \%)$. As well as $\operatorname{IgG}$, serum IgA concentrations were also significantly higher $(P=$ $0.0106)$ in the 9 calves fed the pooled colostrum $(2.6$ $\pm 0.9 \mathrm{~g} / \mathrm{L})$ than in the 7 calves fed the whey solution $(1.5 \pm 0.6 \mathrm{~g} / \mathrm{L}$; Figure 3B). Serum GGT concentrations were also significantly higher $(P=0.0030)$ in the 9 calves fed colostrum $(1,252.4 \pm 353.0 \mathrm{U} / \mathrm{L})$ than in the 7 calves fed the whey solution $(661.0 \pm 304.4 \mathrm{U} / \mathrm{L}$; Figure $3 \mathrm{C}$ ). In contrast, serum total protein concentrations did not vary $(P=0.1931)$ between the 9 calves fed the colostrum $(4.7 \pm 0.4 \mathrm{~g} / \mathrm{L})$ and the 7 calves fed the whey solution $(4.4 \pm 0.3 \mathrm{~g} / \mathrm{L}$; Figure 3D). On the other hand, serum IgG, GGT, IgA, and total protein of the calf that produced small curds were $2.7 \mathrm{~g} / \mathrm{L}, 228.9$ $\mathrm{U} / \mathrm{L}, 1.2 \mathrm{~g} / \mathrm{L}$, and $4.8 \mathrm{~g} / \mathrm{L}$, respectively.

The present study demonstrates that neonatal calves can also produce a large mass of curd in the abomasum after first ingestion of the first-milking colostrum. Considering the detection of $\alpha-\mathrm{LA}$ and $\beta-\mathrm{LG}$, but not $\alpha-\mathrm{CN}$ and $\beta-\mathrm{CN}$, in control abomasal fluid samples of 3 calves with a large curd $2 \mathrm{~h}$ after ingestion, the whole colostrum seemed to be completely coagulated to form a large curd in the abomasum. Although abomasa of neonatal calves may contain amniotic fluid with slightly alkaline $\mathrm{pH}$ (Javed and Wright, 1990) that decreases hydrolytic activities of chymosin whose optimum $\mathrm{pH}$ for curd formation is 5.3 to 6.3 (Foltmann, 1970), our in vitro study found that at least $50 \%$ amniotic fluid in the colostrum did not influence coagulation. On the other hand, it is reported that milk coagulation activity is expressed in the abomasum of fetal calves from $6 \mathrm{mo}$ of gestation and markedly increased after birth (Pang and Ernstrom, 1986). The acidic pH $(1.6 \pm 0.21)$ of the abomasum before feeding increased to $\mathrm{pH}$ of 6.2 to 6.5 , optimum $\mathrm{pH}$ of chymosin, immediately after feeding the colostrum (Birǵele et al., 2005). We conclude that abomasal conditions in neonatal calves are ready for curd formation after birth.

Before the experiments, we hypothesized that there may be negative factors associated with curd formation in first-milking colostrum because it is reported that rennet clotting time is significantly longer in the first-milking colostrum than in subsequent milking colostrum and milk (Tsioulpas et al., 2007; Wroński and Sosnowska, 2007). However, this hypothesis was rejected based on our data that a total of 12 of 13 calves fed the same pooled first-milking colostrum produced a large curd.

Serum levels of IgG and IgA and GGT and AEA of IgG were significantly higher in calves fed the colostrum $(3.8 \pm 1.6 \mathrm{~g} / \mathrm{L}, 2.6 \pm 0.9 \mathrm{~g} / \mathrm{L}, 1,252.4 \pm 353.0 \mathrm{U} / \mathrm{L}$, and $11.1 \pm 1.5 \%$, respectively) than in calves fed the whey solution $(2.1 \pm 0.6 \mathrm{~g} / \mathrm{L}, 1.5 \pm 0.6 \mathrm{~g} / \mathrm{L}, 661.0 \pm$ $304.4 \mathrm{U} / \mathrm{L}$, and $5.7 \pm 0.5 \%$, respectively). Considering the pinocytosis of colostral IgG in the small intestine (Jochims et al., 1994; Kaup et al., 1996) and similar IgG concentrations between the pooled colostrum (54.5 $\mathrm{g} / \mathrm{L})$ and the whey solution $(59.4 \mathrm{~g} / \mathrm{L})$, we strongly suggest that the variations of serum IgG, IgA, and GGT levels between calves are mainly caused by differences in their absorption efficiencies between the presence and absence of curd in their abomasum. Our previous study found abomasal curd was absent in about $28 \%$ (95\% CI, 15-46\%) calves at $2 \mathrm{~h}$ after feeding, but could not find significant differences in blood parameters such as serum triglyceride, blood urea nitrogen, and glucose between calves with curd formation $(12.4 \pm 2.4,13.8 \pm$ 0.9 , and $90.5 \pm 5.1 \mathrm{mg} / \mathrm{dL}$, respectively) and without curd formation $(14.4 \pm 4.2,12.1 \pm 1.0$, and $104.3 \pm$ $11.1 \mathrm{mg} / \mathrm{dL}$, respectively; Miyazaki et al., 2010). We conclude that curd formation would be positively involved in efficient absorption of colostrum IgG and IgA in neonatal calves.

Because curd was detectable in the abomasum more than $8 \mathrm{~h}$ after the first ingestion of colostrum, curd contents such as caseins and lipids would be retained in the abomasum for several hours after ingestion. In addition, we propose that some of the whey contents including IgG may be also retained with the curd in the abomasum for several hours. Our in vitro experiments showed that weights of curd produced from colostrum gradually decreased over time because of releasing the liquid, and IgG concentrations of liquid phases are almost equal before and after curd formation (Figure 4). These suggest that curd works like a sponge soaking the whey, keeps the whey for several hours in the abomasum, and gradually releases the whey over time. Because the size of abomasal curd decreased slightly from $2 \mathrm{~h}$ after the ingestion, a portion of whey may be kept in the curd for several hours and gradually released into the abomasal fluid before transfer from the abomasum to the small intestine for efficient absorption.

In contrast, there would be no materials to retain the whey in the abomasum of calves without curd forma- 

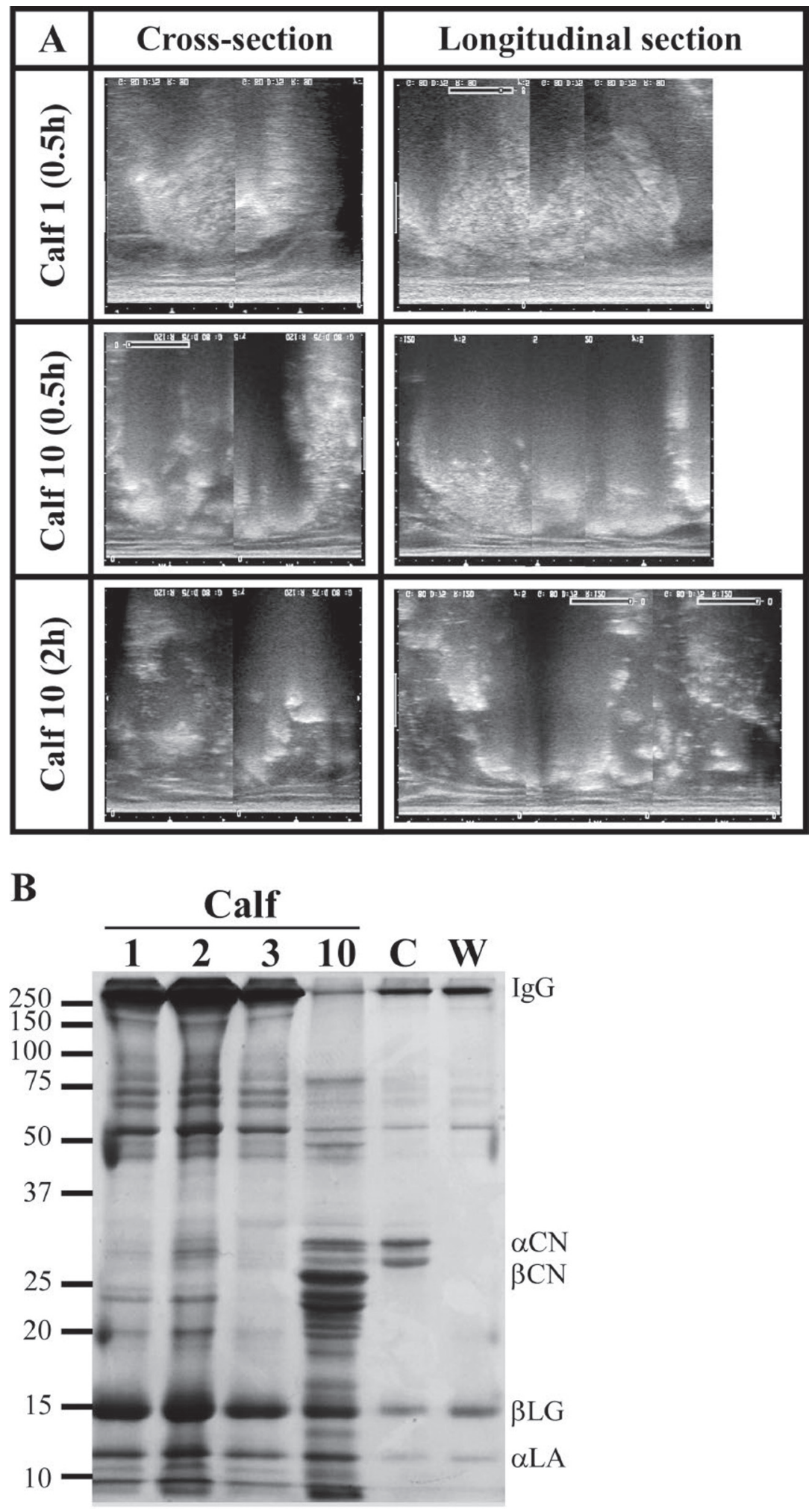

Figure 2. Abomasal contents of a calf exhibiting incomplete curd formation and control calves exhibiting curd formation after ingestion of the pooled colostrum. (A) Ultrasonographic images of the abomasal contents of calf 1 and 10 fed the pooled colostrum. Time indicates hours after feeding. Upper, lower, right, and left of cross-sectional images correspond to dorsal, ventral, right, and left of calf bodies, respectively. Upper, lower, right, and left of longitudinal sectional images correspond to dorsal, ventral, caudal, and cranial of calf bodies, respectively. (B) SDS-PAGE (12\% gel) under nonreducing conditions of abomasal fluid samples obtained from calf $1,2,3$, and 10 . Each lane contains $20 \mu \mathrm{g}$ of protein. The gel was stained with Coomassie Brilliant Blue R-250. C = colostrum; $\mathrm{W}=$ whey. 
A

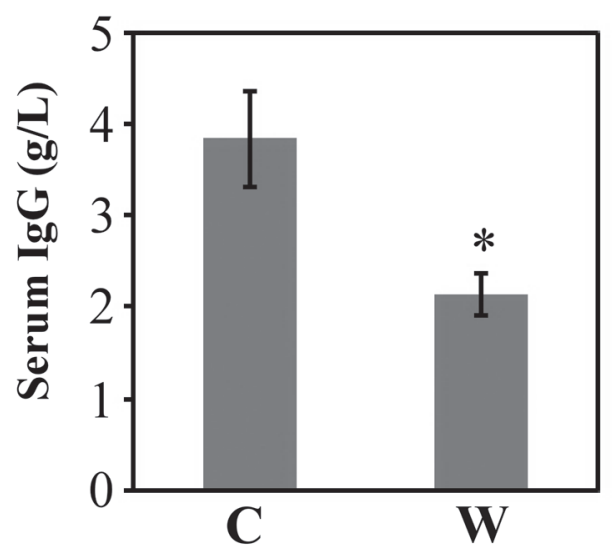

C

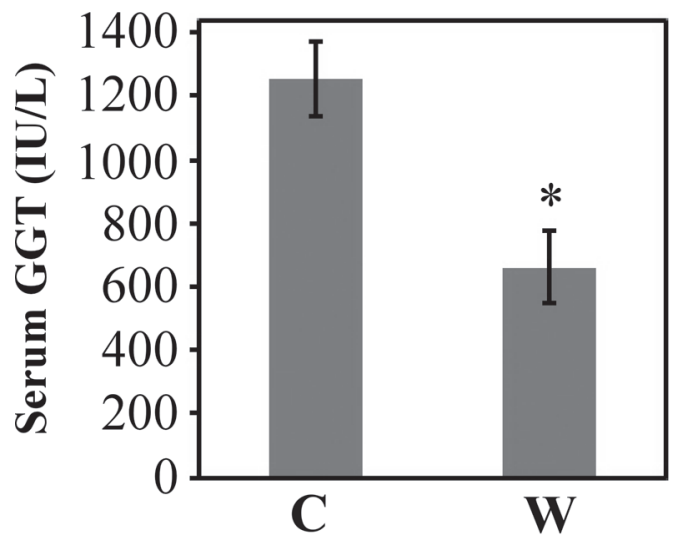

B

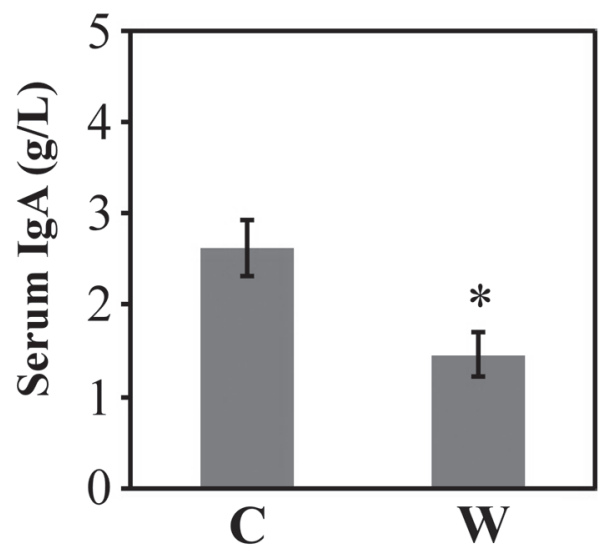

D

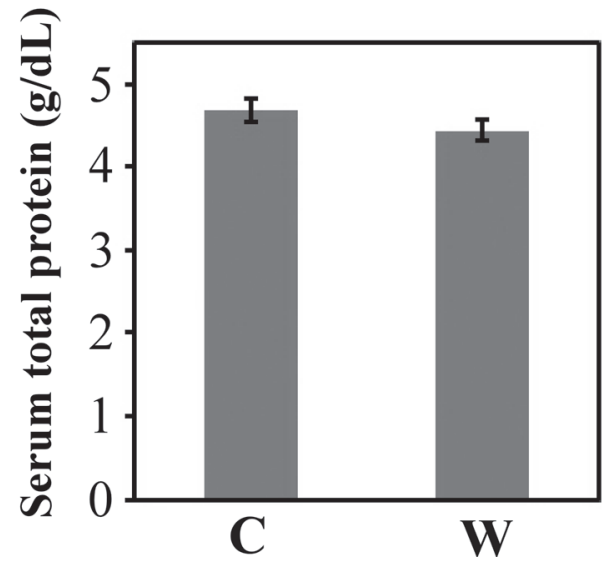

Figure 3. Serum levels of IgG, IgA, $\gamma$-glutamyl transferase (GGT), and total protein in calves between 6 and $7 \mathrm{~h}$ after feeding the pooled colostrum $(\mathrm{C})$ or the whey $(\mathrm{W})$ solution. Data are expressed as mean \pm SE. ${ }^{*}$ Asterisks indicate a significant difference $(P<0.05)$.

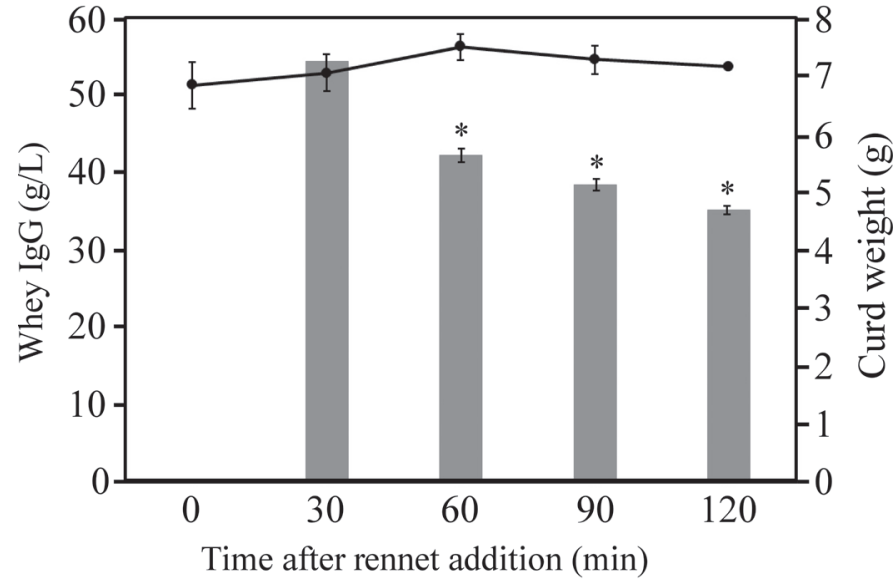

Figure 4. Whey IgG concentrations (line) and curd weights (bars) in in vitro rennet coagulation tests of the pooled colostrum. Ten milliliters of the pooled colostrum was incubated with $200 \mu \mathrm{L}$ of $100 \mathrm{mg} /$ $\mathrm{mL}$ rennet solution at $38^{\circ} \mathrm{C}$. The $\mathrm{IgG}$ concentrations of liquid phases were measured at $0,30,60,90$, and 120 min after the incubation. The curd on the sieve was weighed every $30 \mathrm{~min}$. Data are expressed as mean \pm SE. Asterisks indicate significant differences compared with the weight of the curd at $30 \mathrm{~min}(P<0.05)$. tion. It is reported that an absence of curd formation causes rapid emptying of milk replacer from the abomasum in calves (Cruywagen et al., 1990). Faster abomasal emptying rates were associated with increased AEA of ingested colostral IgG in neonatal calves (Mokhber-Dezfooli et al., 2012). We think that immunoglobulins in the colostrum may be transferred from the abomasum to the small intestine faster in calves without curd formation as compared with calves with curd formation. This speculation may be supported by the result of abomasal fluid analysis that protein and IgG contents in the abomasal fluid were markedly lower in the calf with incomplete curd formation than control calves with a large curd. Calves exhibiting incomplete and no curd formation may be unable to absorb colostrum IgG efficiently by intestinal pinocytosis.

In this study, we found significant differences on AEA of IgG between calves fed the colostrum and the whey solution. However a recent similar study showed no significant difference on AEA of IgG between the calves fed the colostrum and the whey solution (Ver- 
hegghe et al., 2017). In our experiments, we fed $2 \mathrm{~L}$ of the colostrum or the whey solution only once to calves within $4 \mathrm{~h}$ after birth, whereas they fed $2 \mathrm{~L}$ of the colostrum or the whey solution 5 times within $48 \mathrm{~h}$ after birth. In addition, we compared AEA of IgG between the 2 groups using serum samples obtained at $6 \mathrm{~h}$ after the ingestion, whereas they did it using serum samples obtained at $72 \mathrm{~h}$ after birth. Furthermore, they used the whey solution in which $\mathrm{CN}$ bands were detected by SDS-PAGE. In contrast, we used the whey solution in which CN bands were under the detection limit in SDSPAGE. These differences between our experiment and their experiment should explain the conflicting results.

One neonatal calf exhibited incomplete curd formation in that the entire colostrum did not coagulate into a large curd and a portion of the colostrum remained as its residue $\alpha$-caseins and $\beta$-caseins detectable from the abomasal fluid. The calf exhibited low levels of serum IgG, GGT, and IgA. Such neonatal calves may be useful to interpret our recent metabolomics data that there is individual variation in temporal changes of serum IgG and oligosaccharides including lactose even among calves that were fed the same pooled colostrum, and the maximum concentration of serum $\operatorname{IgG}$ and the time at which the maximum concentration was reached were different among calves (Miyazaki et al., 2017). We suggest that the gastrointestinal function for curd formation may congenitally vary between individuals, and incomplete curd formation may result in inefficient absorption of colostrum contents including IgG and oligosaccharides. Further studies such as serum metabolomics with evaluation of curd formation in each neonatal calf will be necessary to conclude how incomplete curd formation is involved in absorption and metabolism of colostrum contents.

In conclusion, neonatal calves produce a large mass of curd by first ingestion of first-milking colostrum, but about $10 \%(95 \%$ CI, 2-40\%) of neonatal calves may exhibit incomplete curd formation. Curd formation would enable neonatal calves to efficiently absorb IgG, IgA, and GGT from the colostrum. This may be because abomasal curd retains not only curd contents but also some whey contents for several hours in the abomasum of neonatal calves. These findings improve our understanding of physiology and metabolism in neonatal calves.

\section{ACKNOWLEDGMENTS}

This work was supported in part by Grant-in-Aid for Scientific Research on Priority Areas from the Japan Society for the Promotion of Science (JSPS; grant 12J40129). T.M. was supported by a Grant-in-Aid for JSPS fellows. We thank S. Sato from Iwate University for invaluable discussion and M. Sato from Iwate University for technical support in this experiment.

\section{REFERENCES}

Birǵele, E., A. Ilgaža, D. Keidāne, and A. Mugurēvičs. 2005. The functional state of the stomach in calves in the first month of postnatal life. Pages 219-224 in the XIIth Intl. Congress ISAH 2005 Anim. and Environment Proc. Vol. 1. Int. Soc. Anim. Hygiene and Anim. Sci. Warsaw Agri. Univ., Warsaw, Poland.

Cabral, R. G., M. A. Cabral, C. E. Chapman, E. J. Kent, D. M. Haines, and P. S. Erickson. 2014. Colostrum replacer feeding regimen, addition of sodium bicarbonate, and milk replacer: The combined effects on absorptive efficiency of immunoglobulin $\mathrm{G}$ in neonatal calves. J. Dairy Sci. 97:2291-2296.

Cabral, R. G., C. E. Chapman, D. M. Haines, A. F. Brito, and P. S. Erickson. 2011. Addition of varying amounts of sodium bicarbonate to colostrum replacer: Effects on immunoglobulin G absorption and serum bicarbonate in neonatal calves. J. Dairy Sci. 94:5656-5660.

Cabral, R. G., E. J. Kent, D. M. Haines, and P. S. Erickson. 2012. Addition of sodium bicarbonate to either 1 or 2 feedings of colostrum replacer: effect on uptake and rate of absorption of immunoglobulin G in neonatal calves. J. Dairy Sci. 95:3337-3341.

Cruywagen, C. W. 1990. Effect of curd forming of colostrum on absorption of immunoglobulin G in newborn calves. J. Dairy Sci. 73:3287-3290.

Cruywagen, C. W., G. J. Brisson, and H. H. Meissner. 1990. Casein curd-forming ability and abomasal retention of milk replacer components in young calves. J. Dairy Sci. 73:1578-1585.

Elizondo-Salazar, J. A., and A. J. Heinrichs. 2009. Feeding heat-treated colostrum to neonatal dairy heifers: effects on growth characteristics and blood parameters. J. Dairy Sci. 92:3265-3273.

Foltmann, B. 1970. Prochymosin and chymosin (prorennin and rennin). Methods Enzymol. 19:421-436.

Furman-Fratczak, K., A. Rzasa, and T. Stefaniak. 2011. The influence of colostral immunoglobulin concentration in heifer calves' serum on their health and growth. J. Dairy Sci. 94:5536-5543.

Godden, S. 2008. Colostrum management for dairy calves. Vet. Clin. North Am. Food Anim. Pract. 24:19-39.

Gregory, N. G. 2003. Effect of enhancing curd formation during the first colostrum feed on absorption of gamma glutamyl transferase by newborn calves. Aust. Vet. J. 81:549-552.

Halleran, J., H. J. Sylvester, and D. M. Foster. 2017. Short communication: Apparent efficiency of colostral immunoglobulin G absorption in Holstein heifers. J. Dairy Sci. 100:3282-3286.

Javed, M. H., and R. W. Wright. 1990. Bovine amniotic and allantoic fluids for the culture of murine embryos. Theriogenology 34:445460.

Jochims, K., F. J. Kaup, W. Drommer, and M. Pickel. 1994. An immunoelectron microscopic investigation of colostral $\operatorname{IgG}$ absorption across the intestine of newborn calves. Res. Vet. Sci. 57:75-80.

Kaup, F. J., W. Drommer, K. Jochims, and M. Pickel. 1996. Ultrastructure of pre- and postcolostral enterocytes of the newborn calf. Anat. Histol. Embryol. 25:249-255.

Longenbach, J. I., and A. J. Heinrichs. 1998. A review of the importance and physiological role of curd formation in the abomasum of young calves. Anim. Feed Sci. Technol. 73:85-97.

Miyazaki, T., M. Miyazaki, J. Yasuda, and K. Okada. 2009. Ultrasonographic imaging of abomasal curd in preruminant calves. Vet. J. 179:109-116.

Miyazaki, T., M. Miyazaki, J. Yasuda, and K. Okada. 2010. No abomasal curd formation in pre-ruminant calves after ingestion of a clotting milk replacer. Vet. J. 183:205-209.

Miyazaki, T., K. Okada, T. Yamashita, and M. Miyazaki. 2017. Twodimensional gas chromatography time-of-flight mass spectrometry-based serum metabolic fingerprints of neonatal calves before and after first colostrum ingestion. J. Dairy Sci. https://doi. org/10.3168/jds.2017-12557. In press. 
Mokhber-Dezfooli, M. R., M. Nouri, M. Rasekh, and P. D. Constable. 2012. Effect of abomasal emptying rate on the apparent efficiency of colostral immunoglobulin G absorption in neonatal HolsteinFriesian calves. J. Dairy Sci. 95:6740-6749.

Morrill, K. M., S. P. Marston, N. L. Whitehouse, M. E. Van Amburgh, C. G. Schwab, D. M. Haines, and P. S. Erickson. 2010. Anionic salts in the prepartum diet and addition of sodium bicarbonate to colostrum replacer, and their effects on immunoglobulin G absorption in the neonate. J. Dairy Sci. 93:2067-2075.

Okada, K., J. Kato, T. Miyazaki, K. Ikuta, Y. Naito, and J. Yasuda. 2009. The evaluation of the curd forming ability of milk replacers. Anim. Sci. J. 80:12-18.

Osaka, I., Y. Matsui, and F. Terada. 2014. Effect of the mass of immunoglobulin (Ig) $\mathrm{G}$ intake and age at first colostrum feeding on serum IgG concentration in Holstein calves. J. Dairy Sci. 97:66086612.

Pang, S. H., and C. A. Ernstrom. 1986. Milk clotting activity in bovine fetal abomasa. J. Dairy Sci. 69:3005-3007.

Quigley, J. D. 3rd, and J. J. Drewry. 1998. Nutrient and immunity transfer from cow to calf pre- and postcalving. J. Dairy Sci. 81:2779-2790.
Stott, G. H., and A. Fellah. 1983. Colostral immunoglobulin absorption linearly related to concentration for calves. J. Dairy Sci 66:1319-1328.

Stott, G. H., and B. E. Menefee. 1978. Selective absorption of immunoglobulin IgM in the newborn calf. J. Dairy Sci. 61:461-466.

Tsioulpas, A., A. S. Grandison, and M. J. Lewis. 2007. Changes in physical properties of bovine milk from the colostrum period to early lactation. J. Dairy Sci. 90:5012-5017.

Verhegghe, M., G. Rasschaert, L. Herman, K. Goossens, L. Vandaele, K. De Bleecker, G. Vlaemynck, M. Heyndrickx, and J. De Block. 2017. Reduction of Mycobacterium avium ssp. paratuberculosis in colostrum: Development and validation of 2 methods, one based on curdling and one based on centrifugation. J. Dairy Sci. https:// doi.org/10.3168/jds.2016-12355. In press.

Wroński, M., and W. Sosnowska. 2007. Physiochemical properties of colostrum and milk from Angus and Black-and-White cows during the first ten days after calving. Pol. J. Nat. Sc. 22:620-632.

Yang, M., Y. Zou, Z. H. Wu, S. L. Li, and Z. J. Cao. 2015. Colostrum quality affects immune system establishment and intestinal development of neonatal calves. J. Dairy Sci. 98:7153-7163. 